\title{
Efeito de sistemas de cultivo na estabilidade de agregados de um Latossolo Vermelho-Amarelo em Querência, MT(1)
}

\author{
José Carlos Corrêa(2)
}

\begin{abstract}
Resumo - Avaliou-se o efeito de diferentes sistemas de cultivo na estabilidade de agregados em água de um Latossolo Vermelho-Amarelo de textura média, no Município de Querência, Mato Grosso. Foram selecionadas nove áreas contíguas: uma coberta com vegetação de mata natural de transição de cerrado para mata amazônica e as outras com sistemas de cultivos anuais. Coletaram-se amostras indeformadas de solo, para a determinação de estabilidade dos agregados em água, da granulometria, e da matéria orgânica. Ocorreram modificações na estrutura e matéria orgânica do solo, causadas pelos diferentes sistemas de cultivo, a partir do preparo da área para o primeiro plantio. Os maiores fracionamentos de agregados ocorreram nas áreas preparadas com grade aradora e grade niveladora para o monocultivo da soja durante quatro e seis anos. O plantio direto da soja sobre a palhada do milheto, por dois anos consecutivos, proporcionou maior estabilidade de agregados do solo. A porcentagem de matéria orgânica correlacionou-se positivamente com a porcentagem de agregados estáveis em água maiores que $2 \mathrm{~mm}$, com o diâmetro médio ponderado dos agregados e com o grau de floculação.
\end{abstract}

Termos para indexação: solo, matéria orgânica, grade aradora, grade niveladora, plantio direto.

Effect of cropping systems on the stability of Red-Yellow Latosol aggregates in Querência, Mato Grosso, Brazil

\begin{abstract}
The effect of different cropping systems on the water aggregates stability of a Red-Yellow Latosol with medium texture was studied in Querência county, Mato Grosso State, Brazil. Nine contiguous areas were selected: one covered with natural "cerrado" vegetation transient to Amazon forest, and others with annual cropping systems. Undisturbed soil samples were collected for determining the stability in water, granulometric analysis and organic matter. Modifications in the structure and soil organic matter caused by different cropping systems were observed from the beginning of soil preparation to the first planting. The greatest fractioning of aggregates occurred in areas prepared with disc plowing and disc harrowing for monocropping of soybean from four to six years. The direct planting of soybean over millet residue for two continuous years resulted in a greater stability of the soil aggregates. There was a positive correlation between the organic matter and the soil aggregates with an average diameter higher than $2 \mathrm{~mm}$ of the aggregates and the flocculation grade
\end{abstract}

Index terms: soil, organic matter, disc ploughs, disc harrows, direct sowing.

\section{Introdução}

O Município de Querência, conforme Projeto DNPM (Departamento Nacional de Produção Mineral, 1981a), está localizado numa larga zona de transição ou zonoecotonos. A cobertura vegetal do município é composta de $15 \%$ de cerrados, $70 \%$ de

\footnotetext{
(1) Aceito para publicação em 28 de maio de 2001

(2) Embrapa-Centro de Pesquisa Agropecuária dos Cerrados (CPAC), Caixa Postal 08223, CEP 73301-970 Planaltina, DF. E-mail: correa@cpac.embrapa.br
}

matas de transição e $10 \%$ de florestas tropicais que fazem parte da Amazônia legal. Às margens dos rios e dos córregos há formação de varjões (5\%), onde predominam galerias e matas formadas por árvores de grande porte (Empresa Mato-Grossense de Pesquisa, Assistência Técnica e Extensão Rural S/A, 1996). Neste contexto, o município assume uma particular importância ecológica. São aproximadamente 1.750.553 hectares (área total do município) que estão sendo integrados ao processo produtivo, pela colonização iniciada em 1985 (Empresa MatoGrossense de Pesquisa, Assistência Técnica e 
Extensão Rural S/A, 1996). O principal solo da região é o Latossolo Vermelho-Amarelo distrófico (com horizonte moderadamente espesso e teores médios de matéria orgânica), associado a Areias Quartzosas e a Latossolo Vermelho-Escuro distrófico e álico. Esses solos são de baixa fertilidade natural e alta saturação de alumínio tóxico às plantas (Departamento Nacional de Produção Mineral, 1981a, 1981b). A precipitação média anual, nos últimos dez anos, conforme Corrêa (1999), foi de $1.850 \mathrm{~mm}$, e a mínima (1.589 mm) ocorreu em 1987 e a máxima (2.200 mm) em 1994. As chuvas concentram-se no período de outubro a abril, com $75 \%$ de ocorrência entre os meses de novembro a março. Nos períodos secos do ano, compreendendo os meses de maio a setembro, há ocorrência de precipitações inferiores a $60 \mathrm{~mm}$.

As operações de desmatamento das áreas são realizadas através de correntão puxado por dois tratores de esteiras. Após o desmatamento, segue-se a limpeza da área, pela queima da vegetação derrubada, destocamento, enleiramento e catação mecanizada de raízes. O preparo da área para o primeiro cultivo (arroz) é feito com grade aradora pesada, de discos recortados de 30 polegadas, que trituram e incorporam os restos vegetais. Em algumas situações é utilizada uma grade mais leve para nivelar o terreno. $\mathrm{O}$ uso intensivo e generalizado da grade aradora e grade niveladora na região, buscando uma condição favorável à semeadura, entretanto, contribuem para promover modificações na estrutura dos solos. Conforme Carpenedo \& Mielniczuk (1990), o solo, quando submetido a cultivos intensivos, tende a perder a estrutura original pelo fracionamento dos agre- gados maiores em unidades menores, com conseqüente redução de macroporos e aumento de microporos e da densidade. A magnitude com que as alterações ocorrem depende do tipo de solo e dos sistemas de manejo utilizados. O efeito mais nocivo é atribuído aos sistemas de manejo que adotam revolvimento intensivo de solos, o que afeta o teor de matéria orgânica, um dos principais agentes de formação e estabilização dos agregados. Do ponto de vista agrícola, a estrutura do solo é um dos atributos mais importantes, pois está relacionada com a disponibilidade de ar e água às raízes das plantas, com o suprimento de nutrientes, com a resistência mecânica do solo à penetração, e com o desenvolvimento do sistema radicular. A manutenção de um bom estado de agregação e estabilidade e, conseqüentemente, de uma boa estrutura, é condição primordial para garantir altas produtividades agrícolas.

O presente trabalho teve como objetivo estudar o efeito de diferentes cultivos anuais na estabilidade de agregados em um Latossolo Vermelho-Amarelo de textura média.

\section{Material e Métodos}

O estudo foi realizado num Latossolo VermelhoAmarelo de textura média, localizado no Município de Querência, a nordeste do Estado de Mato Grosso, entre os meridianos $52^{\circ} 5^{\prime} 0^{\prime \prime}$ e $53^{\circ} 53^{\prime} 0^{\prime \prime}$ e os paralelos $11^{\circ} 10^{\prime} 5^{\prime \prime}$ e $13^{\circ} 8^{\prime} 5^{\prime \prime}$

Numa propriedade agrícola foram selecionadas nove áreas contíguas (Tabela 1). Nas áreas cultivadas, a mata natural foi derrubada com correntão e queimada. Em seguida, essas áreas foram limpas por destoca mecânica,

Tabela 1. Seqüência de cultivos num Latossolo Vermelho-Amarelo no Município de Querência, MT.

\begin{tabular}{cllllll}
\hline \multirow{2}{*}{ Área } & \multicolumn{5}{c}{ Cultivo ${ }^{(1)}$} \\
\cline { 2 - 6 } & \multicolumn{1}{c}{1993} & \multicolumn{1}{c}{1994} & \multicolumn{1}{c}{1995} & \multicolumn{1}{c}{1996} & \multicolumn{1}{c}{1998} \\
\hline 1 & Mata natural & Mata natural & Mata natural & Mata natural & Mata natural & Arroz (PC) \\
2 & Arroz (PC) & Soja (PC) & Soja (PC) & Soja (PC) & Soja (PC) & Soja (PC) \\
3 & Mata natural & Mata natural & Mata natural & Mata natural & Arroz (PC) & Soja (PD1) \\
4 & Mata natural & Arroz (PC) & Arroz (PC) & Soja (PC) & Soja (PD1) & Soja (PD2) \\
5 & Mata natural & Mata natural & Arroz (PC) & Soja (PC) & Arroz (PC) & Soja (PD3) \\
6 & Mata natural & Mata natural & Mata natural & Mata natural & Mata natural & Mata natural \\
7 & Mata natural & Mata natural & Mata natural & Arroz (PC) & Soja (PD2) & Soja (PD2) \\
8 & Mata natural & Mata natural & Mata natural & Mata natural & Arroz (PC) & Soja (PD2) \\
9 & Mata natural & Mata natural & Arroz (PC) & Soja (PC) & Soja (PC) & Soja (PC) \\
\hline
\end{tabular}

(1) PC: preparo convencional de solo por meio de uma a duas passadas com grade aradora e grade niveladora; PD1: plantio direto da soja sobre a palhada do arroz e do capim-amargoso (Digitaria insularis (L.) Mea ex Ekman); PD2: plantio direto da soja sobre palhada do milheto safrinha; PD3: plantio direto da soja sobre palhada do capim-amargoso (Digitaria insularis (L.) Mea ex Ekman) 
enleiramento, e catação mecanizada das raízes: Área 1 desmatada em 1998 (o solo foi preparado com grade aradora e grade niveladora e realizado o primeiro plantio com arroz); Área 2: desmatada em 1993 (o solo foi preparado com grade aradora e grade niveladora durante seis anos, para os plantios de arroz no primeiro ano e soja nos anos subseqüentes); Área 3: desmatada em 1997 e cultivada durante dois anos (o solo foi preparado com grade aradora e grade niveladora para o plantio de arroz, e no ano seguinte foi realizado o plantio direto da soja sobre a palhada do arroz e do capim-amargoso (Digitaria insularis L.)); Área 4: desmatada em 1994 e cultivada durante cinco anos (o solo foi preparado com grade aradora e grade niveladora para o plantio do arroz (dois anos) e soja (um ano), e no quarto e quinto ano foram realizados plantios direto da soja sobre palhada do milheto); Área 5: desmatada em 1995 e cultivada durante quatro anos (o solo foi preparado com grade aradora e grade niveladora para o cultivo do arroz no primeiro ano, soja no segundo ano, arroz no terceiro ano e, no quarto ano, plantio direto da soja sobre a palhada do capimamargoso); Área 6: coberta com vegetação de mata natural de transição de cerrado para mata amazônica; Área 7 : desmatada em 1996 e cultivada durante três anos (o solo foi preparado com grade aradora e grade niveladora para o plantio de arroz no primeiro ano, e nos dois anos seguintes o plantio direto da soja sobre a palhada do milheto); Área 8: desmatada em 1997 e cultivada durante dois anos (o solo foi preparado com grade aradora e grade niveladora para o plantio do arroz no primeiro ano e, no segundo ano, foi realizado o plantio direto da soja sobre a palhada do milheto); Área 9 desmatada em 1995 e cultivada durante quatro anos (o solo foi preparado com grade aradora e grade niveladora durante quatro anos para os plantios de arroz no primeiro ano e soja nos anos seguintes).

Em fevereiro de 1999 foram coletadas ao acaso, nas profundidades de 0 a $15 \mathrm{~cm}$ e 15 a $30 \mathrm{~cm}$, amostras de solo indeformadas (forma de blocos), em dez pontos de cada área selecionada. No momento da amostragem o solo encontrava-se friável. No laboratório, a amostra úmida e friável foi passada na peneira de $4,76 \mathrm{~mm}$ (4 mesh) e retida na de $2 \mathrm{~mm}$. Parte desta amostra foi utilizada para as análises de estabilidade de agregados, e a outra parte foi secada ao ar e posteriormente destorroada e passada novamente na peneira de $2 \mathrm{~mm}$ para as análises de carbono e análise textural. A análise da estabilidade dos agregados foi determinada pelo método descrito por Kemper \& Chepil (1965), que utiliza o aparelho de oscilação vertical. Foram colocados $50 \mathrm{~g}$ de cada amostra na peneira superior de um jogo de peneiras com abertura de malhas de 2,0, 1,0, 0,5, 0,25 e $0,10 \mathrm{~mm}$. O nível de água no aparelho foi ajustado na posição mais alta das peneiras, para que a água cobrisse ape- nas o fundo da peneira de $2 \mathrm{~mm}$. O aparelho foi ligado durante 30 minutos, e a massa do material retido em cada peneira, após a pesagem, foi corrigida para massa do solo seco, em estufa a $105^{\circ} \mathrm{C}$. O diâmetro médio ponderado (DMP) dos agregados foi calculado a partir do somatório dos produtos entre o diâmetro médio de cada fração de agregado, e a proporção da massa da amostra, que foi obtida por meio da divisão da massa de agregados retidos em cada peneira pela massa da amostra corrigida, em termos de umidade. O carbono orgânico foi determinado segundo método de Walkey \& Black (Allison, 1965), a granulometria e argila dispersa em água conforme método descrito por Day (1965), e a classe textural, conforme Curi et al. (1993).

O delineamento experimental usado foi o inteiramente casualizado. Os resultados obtidos foram submetidos à análise de variância e as médias comparadas pelo teste de Tukey a 5\% de probabilidade. Os solos das áreas cultivadas foram comparados entre si e em relação à testemunha absoluta, representada pelo solo coberto com vegetação natural de transição.

\section{Resultados e Discussão}

A análise granulométrica revelou que o solo possui textura média com teores de argila que variam de 29 a $34 \%$ (Tabela 2).

Tomando-se a mata natural (Área 6) como condição original de agregação do solo, observa-se que os efeitos dos sistemas de cultivo manifestaram-se mais intensamente sobre os agregados de diâmetro maior que $2 \mathrm{~mm}$, entre 1,0 e 0,5 mm e entre 0,5 e 0,2 mm (Figura 1). As modificações da classe de agregados de maior diâmetro contribuíram não para o surgimento de maiores porcentuais nas classes de menor diâmetro mas na classe intermediária, conforme constataram Carpenedo \& Mielniczuk (1990) e Silva \& Mielniczuk (1998). Na camada superficial (0 a $15 \mathrm{~cm}$ ) do solo sob condições de mata natural (Área 6), 88\% dos agregados são de diâmetro maior que $2 \mathrm{~mm}$. O fracionamento dos agregados do solo (redução da porcentagem de agregados maior de $2 \mathrm{~mm}$ ) ocorreu com o início das práticas de limpeza da área através da destoca e enleiramento e preparo do solo com grade aradora e grade niveladora para o primeiro cultivo do arroz (Área 1) (Figura 1). 
Tabela 2. Análise granulométrica e classe textural do Latossolo Vermelho-Amarelo sob diferentes condições de cultivo no Município de Querência, MT.

\begin{tabular}{|c|c|c|c|c|c|c|}
\hline \multirow[t]{2}{*}{ Área ${ }^{(1)}$} & \multirow{2}{*}{$\begin{array}{l}\text { Profundidade } \\
(\mathrm{cm})\end{array}$} & \multirow[t]{2}{*}{ Argila } & \multirow[t]{2}{*}{ Silte } & \multicolumn{2}{|c|}{ Areia } & \multirow{2}{*}{$\begin{array}{l}\text { Classe } \\
\text { textural }\end{array}$} \\
\hline & & & & Grossa & Fina & \\
\hline & & ------ & & ---------- & ------ & \\
\hline \multirow[t]{2}{*}{1} & $0-15$ & 31 & 0 & 36 & 33 & Média \\
\hline & $15-30$ & 33 & 0 & 35 & 32 & Média \\
\hline \multirow[t]{2}{*}{2} & $0-15$ & 29 & 0 & 34 & 36 & Média \\
\hline & $15-30$ & 33 & 1 & 34 & 32 & Média \\
\hline \multirow[t]{2}{*}{3} & $0-15$ & 29 & 0 & 42 & 29 & Média \\
\hline & $15-30$ & 32 & 0 & 35 & 33 & Média \\
\hline \multirow[t]{2}{*}{4} & $0-15$ & 33 & 1 & 34 & 32 & Média \\
\hline & $15-30$ & 32 & 1 & 33 & 34 & Média \\
\hline \multirow[t]{2}{*}{5} & $0-15$ & 32 & 0 & 34 & 34 & Média \\
\hline & $15-30$ & 33 & 1 & 34 & 32 & Média \\
\hline \multirow[t]{2}{*}{6} & $0-15$ & 31 & 1 & 32 & 36 & Média \\
\hline & $15-30$ & 32 & 1 & 33 & 34 & Média \\
\hline \multirow[t]{2}{*}{7} & $0-15$ & 30 & 0 & 34 & 36 & Média \\
\hline & $15-30$ & 34 & 1 & 35 & 30 & Média \\
\hline \multirow[t]{2}{*}{8} & $0-15$ & 30 & 0 & 34 & 36 & Média \\
\hline & $15-30$ & 34 & 1 & 35 & 30 & Média \\
\hline \multirow[t]{2}{*}{9} & $0-15$ & 32 & 0 & 35 & 33 & Média \\
\hline & $15-30$ & 30 & 0 & 36 & 34 & Média \\
\hline
\end{tabular}

(1)Área 1: arroz (PC); Área 2: arroz (PC), soja (PC), soja (PC), soja (PC), soja (PC), soja (PC); Área 3: arroz (PC), soja (PD sobre palhada do arroz e capimamargoso); Área 4: arroz (PC), arroz (PC), soja (PC), soja (PD sobre palhada do milheto), soja (PD sobre palhada do milheto); Área 5: arroz (PC), soja (PC), arroz (PC), arroz (PC), soja (PD sobre palhada do capim-amargoso); Área 6: mata natural; Área 7: arroz (PC), soja (PD sobre palhada do milheto), soja (PD sobre palhada do milheto); Área 8: arroz (PC), soja (PD sobre palhada do milheto); Área 9: arroz (PC), soja (PC), soja (PC), soja (PC).

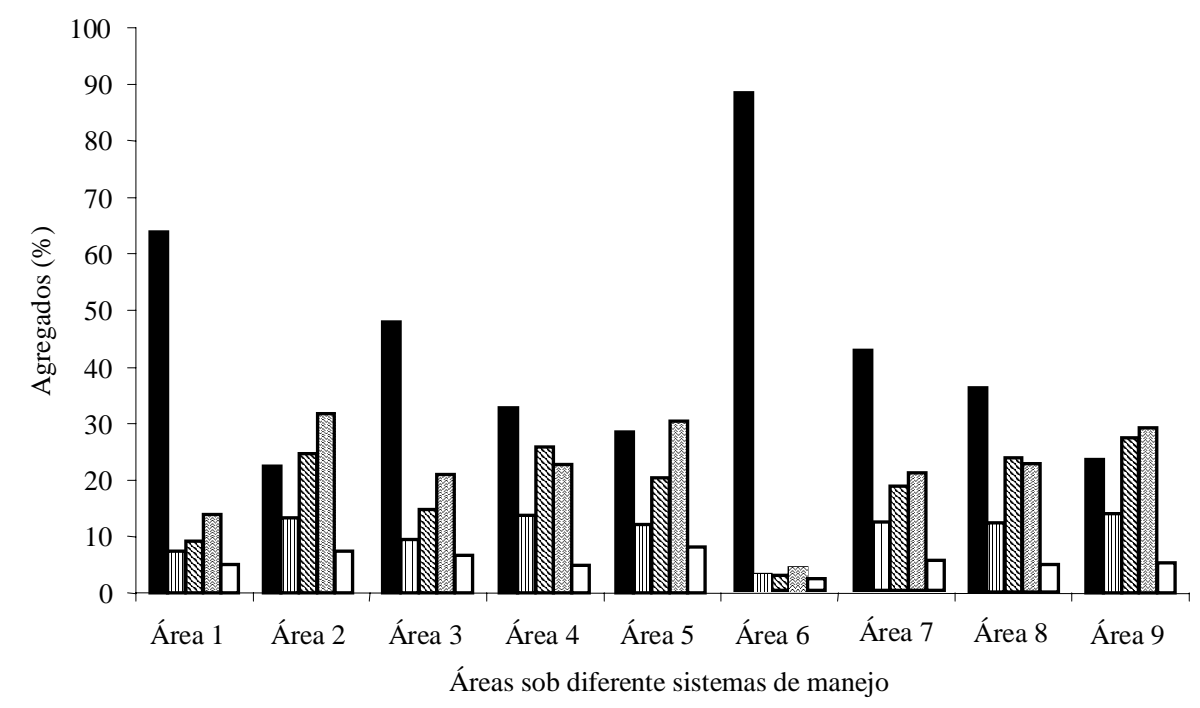

Figura 1. Distribuição de tamanhos de agregados com diâmetros maiores que $2 \mathrm{~mm}(\mathbf{\square}), 1$ a $2 \mathrm{~mm}(\boldsymbol{\square}), 0,5$ a $1,0 \mathrm{~mm}(\boldsymbol{\nabla}), 0,2$ a $0,5 \mathrm{~mm}$ (圆) e 0,1 a $0,2 \mathrm{~mm}$ (口) de um Latossolo VermelhoAmarelo de textura média $(0$ a $15 \mathrm{~cm})$ sob diferentes sistemas de cultivo no Município de Querência, MT. 
Entre os sistemas estudados, os maiores fracionamentos dos agregados do solo ocorreram nas áreas preparadas com a grade aradora e grade niveladora para o monocultivo da soja durante quatro (Área 9) e seis anos (Área 2). O uso contínuo desses implementos, associado ao baixo teor relativo de argila no solo (Tabela 2) e ao monocultivo da soja promoveu, com mais intensidade, alterações na estrutura do solo. Carpenedo \& Mielniczuc (1990) observaram que o cultivo reduziu os agregados maiores que $2 \mathrm{~mm}$ de 58 para $38 \%$ em Latossolo Roxo distrófico e de 35 para $17 \%$ em Latossolo Roxo álico.

Além dessas alterações observou-se, através de aberturas de pequenas trincheiras, a presença de uma camada compactada, a partir dos $15 \mathrm{~cm}$ de profundidade, no solo das áreas preparadas com a grade aradora e grade niveladora. Conforme Dedecek et al. (1986), o maior rendimento nas operações de preparo na região dos cerrados se condicionou ao emprego da grade pesada como principal implemento para essas operações. No entanto, não demoraram a aparecer os problemas decorrentes da compactação dos solos.

No sistema de cultivo da área (Área 4) pelo plantio direto da soja sobre a palhada do milheto por dois anos consecutivos, a porcentagem de agregados maiores que $2 \mathrm{~mm}$ foi de $36,2 \%$ enquanto nos sistemas de cultivo através do preparo de área com grade aradora e grade niveladora, para os plantios sucessivos de soja durante três (Área 9) e cinco anos (Área 2), as porcentagens de agregados maiores que $2 \mathrm{~mm}$ foram de 23,6 e 22,5\%, respectivamente (Figura 1). Portanto, sistemas que adotam menor revolvimento do solo e adição de palhada sobre a superfície podem deter o declínio da qualidade estrutural dos solos cultivados, bem como promover a recuperação dos já degradados. Segundo Eltz et al. (1989), o plantio direto proporciona maior tamanho de agregados estáveis, quando comparado com o sistema convencional de preparo do solo, possivelmente devido à não-destruição mecânica dos agregados pelos implementos de preparo do solo, e à proteção que a palha oferece à superfície do solo. Campos et al. (1995) também encontraram maior porcentagem de agregados estáveis em água, cerca de $45 \%$, na clas- se de maior tamanho 8,0 a 4,76 mm no plantio direto, enquanto no sistema convencional a maior concentração de agregados estáveis em água se verificou na classe de 1,00 a 0,21 mm, o que está de acordo com os resultados obtidos no presente trabalho. Segundo Oades (1984), o cultivo intensivo, por favorecer maior taxa de oxidação, resulta na diminuição do teor de matéria orgânica do solo. Essas alterações provocam redução na estabilidade dos macroagregados e aumento na dispersão das argilas, uma vez que, de acordo com Tisdall \& Oades (1982), o acúmulo de agregados nas classes inferiores a $1 \mathrm{~mm}$ de diâmetro, nos tratamentos sob cultivo, ocorre porque esses agregados são estáveis ao rápido umedecimento. Alvarenga et al. (1986) concluíram que a manutenção dos restos culturais sobre a superfície do solo favoreceu o desenvolvimento de agregados maiores que $2 \mathrm{~mm}$.

Os sistemas de cultivo afetaram significativamente a porcentagem de matéria orgânica (Tabela 3). As práticas de desmatamento e preparo da área para o primeiro cultivo do arroz (Área 1) reduziram em $20 \%$ o teor de matéria orgânica da camada superficial (0 a $15 \mathrm{~cm}$ ) do solo. Nas áreas onde houve um preparo intensivo com a grade aradora e grade niveladora e monocultivo da soja, por períodos de quatro anos (Área 9), e seis anos (Área 2), a redução, em relação à mata natural, foi de 41,3 e $49 \%$, respectivamente. $\mathrm{Na}$ área onde foi realizado o plantio direto da soja sobre a palhada do milheto por dois anos consecutivos (Área 4) o teor de matéria orgânica foi 9,8 e 21\%, respectivamente, superior aos da Área 9 e Área 2.

Na camada superficial, os valores do diâmetro médio ponderado (DMP) dos agregados foram significativamente menores em todos os sistemas de cultivo, principalmente, nas áreas onde o preparo foi mais intensivo, com grade aradora e grade niveladora e monocultivo da soja por quatro (Área 9) e seis anos (Área 2) (Tabela 3). Os sistemas de cultivo dessas áreas (Area 9 e Área 2) reduziram o DMP dos agregados de 63 e 70,5\%, respectivamente, em relação à mata natural. Entre os sistemas de cultivo, o que envolveu a semeadura direta durante dois anos (Área 4) foi o que proporcionou maior valor de DMP. Nessa área, o DMP dos agregados da camada superficial foi 
superior a 10,8 e 28,8\% aos da Área 9 e Área 2, respectivamente. Carpenedo \& Mielniczuk (1990) também obtiveram valores cerca de duas vezes maiores de DMP no sistema plantio direto quando comparado com o convencional. Com relação ao grau de floculação, verifica-se que também houve diferença significativa entre os sistemas de cultivo.

Houve uma tendência de aumento na porcentagem de agregados de diâmetro maior que $2 \mathrm{~mm}$ e no DMP, quando são incrementados os teores de maté- ria orgânica no solo (Tabela 4$)$. Os valores de $\mathrm{R}^{2}$ foram altamente significativos $(0,89 * *)$. Os resultados também mostram que a relação entre o grau de floculação (GF) e a matéria orgânica do solo em estudo foi altamente significativa $\left(\mathrm{R}^{2}=0,72 * *\right)$. Por ser a matéria orgânica um poderoso agente de formação (floculação) e estabilização dos agregados em solos com baixo teor de argila (Tabela 2), é natural encontrar correlações positivas entre as variáveis estudadas (Tisdall \& Oades, 1982).

Tabela 3. Matéria orgânica (\%), agregados com diâmetros maiores que $2 \mathrm{~mm}(\%)$, diâmetro médio ponderado de agregados (DMP) e grau de floculação (\%) nas profundidades de 0-15 cm e 15-30 cm de um Latossolo VermelhoAmarelo, sob diferentes condições de cultivo no Município de Querência, MT $^{(1)}$

\begin{tabular}{|c|c|c|c|c|c|c|c|c|}
\hline \multirow[t]{2}{*}{ Área } & \multicolumn{2}{|c|}{ Matéria orgânica } & \multicolumn{2}{|c|}{ Agregados $>2 \mathrm{~mm}$} & \multicolumn{2}{|c|}{ Grau de floculação } & \multicolumn{2}{|c|}{ DMP } \\
\hline & $0-15$ & $15-30$ & $0-15$ & $15-30$ & $0-15$ & $15-30$ & $0-15$ & $15-30$ \\
\hline 1 & $2,38 b$ & $1,39 b$ & $63,9 b$ & $34,9 b$ & $27,0 \mathrm{~b}$ & $19,6 \mathrm{a}$ & $3,43 b$ & $2,21 b$ \\
\hline 2 & $1,52 \mathrm{~h}$ & $1,10 \mathrm{~g}$ & $22,5 f$ & $14,7 \mathrm{e}$ & $12,2 \mathrm{~g}$ & $6,8 \mathrm{f}$ & $1,71 \mathrm{~g}$ & $1,31 \mathrm{e}$ \\
\hline 3 & $2,29 \mathrm{c}$ & $1,25 \mathrm{~d}$ & $47,9 \mathrm{c}$ & $31,4 b$ & $24,0 \mathrm{c}$ & $17,5 b$ & $2,53 \mathrm{~cd}$ & $2,02 \mathrm{~b}$ \\
\hline 4 & $1,94 \mathrm{e}$ & $1,27 \mathrm{c}$ & $32,8 \mathrm{~cd}$ & $27,7 \mathrm{c}$ & $20,7 \mathrm{e}$ & $18,9 \mathrm{a}$ & $2,26 \mathrm{de}$ & $1,84 \mathrm{c}$ \\
\hline 5 & $1,81 \mathrm{f}$ & $1,11 \mathrm{~g}$ & $28,5 \mathrm{e}$ & $20,9 d$ & $21,1 \mathrm{~d}$ & $13,6 \mathrm{c}$ & $1,88 \mathrm{f}$ & $1,59 \mathrm{~d}$ \\
\hline 6 & $2,98 \mathrm{a}$ & $1,66 \mathrm{a}$ & $88,1 \mathrm{a}$ & $50,6 \mathrm{a}$ & $29,0 \mathrm{a}$ & $11,3 \mathrm{~d}$ & $4,44 \mathrm{a}$ & $2,92 \mathrm{a}$ \\
\hline 7 & $2,26 \mathrm{c}$ & $1,13 \mathrm{f}$ & $42,5 \mathrm{c}$ & $26,6 \mathrm{c}$ & $28,8 \mathrm{a}$ & $11,2 \mathrm{de}$ & $2,73 \mathrm{c}$ & $1,80 \mathrm{c}$ \\
\hline 8 & $1,98 \mathrm{~d}$ & $1,20 \mathrm{e}$ & $36,2 \mathrm{~cd}$ & $25,6 \mathrm{c}$ & $17,9 \mathrm{f}$ & $10,3 \mathrm{e}$ & $2,13 \mathrm{de}$ & $1,79 \mathrm{c}$ \\
\hline 9 & $1,75 \mathrm{~g}$ & $0,93 \mathrm{~h}$ & $23,6 \mathrm{f}$ & $19,2 d$ & $17,9 \mathrm{f}$ & $7,3 \mathrm{f}$ & $1,64 \mathrm{~h}$ & $1,48 \mathrm{~d}$ \\
\hline
\end{tabular}

${ }^{(1)}$ Médias com letras iguais na mesma coluna não diferem entre si a 5\% de probabilidade pelo teste Tukey; Área 1: arroz (PC); Área 2: arroz (PC), soja (PC), soja (PC), soja (PC), soja (PC), soja (PC); Área 3: arroz (PC), soja (PD sobre palhada do arroz e capim-amargoso); Área 4: arroz (PC), arroz (PC), soja (PC), soja (PD sobre palhada do milheto), soja (PD sobre palhada do milheto); Área 5: arroz (PC), soja (PC), arroz (PC), arroz (PC), soja (PD sobre palhada do capim-amargoso); Area 6: mata natural; Area 7: arroz (PC), soja (PD sobre palhada do milheto), soja (PD sobre palhada do milheto); Area 8 arroz (PC), soja (PD sobre palhada do milheto); Área 9: arroz (PC), soja (PC), soja (PC), soja (PC).

Tabela 4. Equações de regressão e coeficiente de determinação $\left(\mathrm{R}^{2}\right)$ entre as porcentagens de agregados com diâmetros maiores que $2 \mathrm{~mm}(\mathrm{D}>2 \mathrm{~mm}$ ), diâmetro médio ponderado de agregados (DMP) e grau de floculação (GF) e porcentagem de matéria orgânica (X) de um Latossolo Vermelho-Amarelo sob diferentes sistemas de cultivo no Município de Querência, MT.

\begin{tabular}{llc}
\hline Parâmetro & \multicolumn{1}{c}{ Equação } & $\mathrm{R}^{2}$ \\
\hline Agregados $>2,0 \mathrm{~mm}$ & $\mathrm{D}>2 \mathrm{~mm}=-58,18+48,05 \mathrm{X}$ & $0,89 * *$ \\
Diâmetro médio ponderado de agregados & $\mathrm{DMP}=-1,78+2,05 \mathrm{X}$ & $0,89 * *$ \\
Grau de floculação & $\mathrm{GF}=-1,86+11,38 \mathrm{X}$ & $0,72 * *$ \\
\hline
\end{tabular}

** Significativo a $1 \%$ de probabilidade 


\section{Conclusões}

1. O desmatamento (por meio do correntão), a limpeza da área (destoca, catação mecânica de raízes, e enleiramento) e o preparo do solo com grade aradora e grade niveladora para o primeiro plantio do arroz reduzem o tamanho de agregados com diâmetro maior que $2 \mathrm{~mm}$ da camada superficial do solo.

2. O sistema de preparo do solo por grades aradora e niveladora e o monocultivo da soja causam maior fracionamento dos agregados do solo.

3. O plantio direto sobre palhada do milheto proporciona maior porcentagem de agregados do solo das áreas anteriormente preparadas com a grade aradora e niveladora.

\section{Referências}

ALLISON, L. E. Organic carbon. In: BLACK, C. A.; EVANS, D. D.; ENSMINGER, L. E.; WHITE, J. L.; CLARK, F. E. (Ed.). Method of soil analysis. Madison: American Society of Agronomy, 1965. v. 2, p. 1372-1376.

ALVARENGA, R. C.; FERNANDES, B.; SILVA, T. C. A.; REZENDE, M. Estabilidade de agregados de um Latossolo sob diferentes métodos de preparo de solo e de manejo da palha do milho. Revista Brasileira de Ciência do Solo, Campinas, v. 10, p. 273-277, 1986

CAMPOS, B. C.; REINERT, D. J.; NICOLODI, R.; RUEDELL, J.; PETRELLE, C. Estabilidade estrutural de um Latossolo Vermelho-Escuro distrófico após sete anos de rotação de culturas e sistemas de manejo. Revista Brasileira de Ciência do Solo, Campinas, v. 19, p. 121-126, 1995.

CARPENEDO, V.; MIELNICZUK, J. Estado de agregação e qualidade de agregados de Latossolos Roxos, submetidos a diferentes sistemas de manejo. Revista Brasileira de Ciência do Solo, Campinas, v. 14, p. 99-105, 1990.

CORREAA, J. C. Diagnóstico dos sistemas de produção em propriedades agrícolas no Município de Querência, MT. Planaltina: Embrapa-CPAC, 1999. 79 p. (Documentos, 2).

CURI, N.; ITURRI LARACH, J. O.; KAMPF, N.; MONIZ, A. C.; FONTES, L. E. F. Vocabulário de Ciência do Solo. Campinas: Sociedade Brasileira de Ciência do Solo, 1993. 90 p
DAY, P. R. Particle fractionation and particle size analysis. In: BLACK, C. A.; EVANS, D. D.; ENSMINGER, L. E.; WHITE, J. L.; CLARK, F. E. (Ed.). Methods of soils analysis. Madison: American Society of Agronomy, 1965. v. 1 , p. 545-567.

DEDECEK, R. A.; PEREIRA, J.; IKE, M.; IWATA, F. Efeito da profundidade de aração inicial, modos de adubação corretiva e sistemas de preparo de solo na produção de soja em solos de cerrados. Revista Brasileira de Ciência do Solo, Campinas, v. 14, p. 173-180, 1986.

DEPARTAMENTO NACIONAL DA PRODUÇÃO MINERAL. Projeto Radambrasil. Folha SC. 22 Tocantins: geologia, geomorfologia, pedologia, vegetação, uso potencial da terra. Rio de Janeiro, 1981a. Mapa de vegetação. (Levantamento de Recursos Naturais, v. 22).

DEPARTAMENTO NACIONAL DA PRODUÇÃO MINERAL. Projeto Radambrasil. Folha SD. 22 Goiás: geologia, geomorfologia, pedologia, vegetação, uso potencial da terra. Rio de Janeiro, 1981b. Mapa de vegetação. (Levantamento de Recursos Naturais, v. 25)

ELTZ, F. L. F.; PEIXOTO, R. T. G.; JASTER, F. Efeitos de sistemas de preparo de solo nas propriedades físicas e químicas de um Latossolo Bruno álico. Revista Brasileira de Ciência do Solo, Campinas, v. 13, p. 259-267, 1989.

EMPRESA MATO-GROSSENSE DE PESQUISA, ASSISTÊNCIA TÉCNICA E EXTENSÃO RURAL S/A (Cuiabá, MT). Querência-MT: estudo da realidade. Querência, 1996.21 p

KEMPER, W. D.; CHEPIL, W. S. Size distribution of aggregation. In: BLACK, C. A.; EVANS, D. D.; ENSMINGER, L. E.; WHITE, J. L.; CLARK, F. E. (Ed.). Methods of soil analysis. Madison: American Society of Agronomy, 1965. v. 1, p. 499-510.

OADES, J. M. Soil organic matter and structural stability: mechanisms and implications for management. Plant and Soil, The Hague, v. 76, n. 1/3, p. 319-337, 1984.

SILVA, I. F.; MIELNICZUK, J. Sistemas de cultivo e características do solo afetando a estabilidade de agregados. Revista Brasileira de Ciência do Solo, Viçosa, MG, v. 22, p. $311-317,1998$.

TISDALL, J. M.; OADES, J. M. Organic matter and water-stable aggregates in soils. Journal of Soil Science, London, v. 33, p. 141-163, 1982. 